\title{
Experimental Verification of Resistance-Demand Approach for Shear of HSC Beams
}

\author{
Ahmed K. El-Sayed ${ }^{1,2), *}$, and Ahmed B. Shuraim ${ }^{3)}$ \\ (Received February 10, 2016, Accepted August 14, 2016, Published online November 18, 2016)
}

\begin{abstract}
The resistance-demand approach has emerged as an effective approach for determining the shear capacity of reinforced concrete beams. This approach is based on the fact that both the shear resistance and shear demand are correlated with flexural tensile strain from compatibility and equilibrium requirements. The basic shear strength, under a given loading is determined from the intersection of the demand and resistance curves. This paper verifies the applicability of resistance-demand procedure for predicting the shear capacity of high strength concrete beams without web reinforcement. A total of 18 beams were constructed and tested in four-point bending up to failure. The test variables included the longitudinal reinforcement ratio, the shear span to depth ratio, and the beam depth. The shear capacity of the beams was predicted using the proposed procedure and compared with the experimental values. The results of the comparison showed good prediction capability and can be useful to design practice.
\end{abstract}

Keywords: shear strength, reinforced concrete beams, resistance, demand, high strength concrete, verification.

\section{Abbreviations}

$A_{s} \quad$ Area of tension reinforcement, $\mathrm{mm}^{2}$

$a_{v} \quad$ Shear span (distance between the concentrated load and the support), $\mathrm{mm}$

$b_{w} \quad$ Web width of the beam, mm

$c^{i} \quad$ Depth of the neutral axis associated to $\varepsilon_{c}^{i}, \mathrm{~mm}$

$d \quad$ Effective depth of tensile reinforcement, $\mathrm{mm}$

$f_{c}^{\prime} \quad$ Specified compressive strength of concrete, $\mathrm{MPa}$

$f_{t} \quad$ Concrete tensile strength, $\mathrm{MPa}$

$h \quad$ Total depth of the beam, mm

$M \quad$ Bending moment, kN.m

$M_{s}^{i} \quad$ Bending moment associated to $\varepsilon_{c}^{i}$, kN.m

$V \quad$ Shear force, $\mathrm{kN}$

$V_{c} \quad$ Shear capacity provided by concrete (concrete contribution), $\mathrm{kN}$

$V_{c r} \quad$ Inclined cracking shear capacity, $\mathrm{kN}$

$V_{D}^{i} \quad$ Shear demand associated to $\varepsilon_{c}^{i}, \mathrm{kN}$

$V_{R}^{i} \quad$ Shear resistance associated to $\varepsilon_{c}^{i}, \mathrm{kN}$

\footnotetext{
${ }^{1)}$ Department of Civil Engineering, Center of Excellence for Concrete Research and Testing, King Saud University, Riyadh 11421, Kingdom of Saudi Arabia. *Corresponding Author; E-mail: ahelsayed@ksu.edu.sa

${ }^{2)}$ Housing and Building National Research Center, Giza, Egypt.

${ }^{3)}$ Department of Civil Engineering, King Saud University, Riyadh 11421, Kingdom of Saudi Arabia.

Copyright $($ The Author(s) 2016. This article is published with open access at Springerlink.com
}

$V_{R D} \quad$ Basic shear capacity (the intersection of the resistance and demand curves), $\mathrm{kN}$

$V_{R D}^{*} \quad$ Resistance-demand shear capacity, $\mathrm{kN}$

$V_{s} \quad$ Shear capacity provided by stirrups, $\mathrm{kN}$

$V_{u} \quad$ Ultimate shear capacity, $\mathrm{kN}$

$V_{u} \exp \quad$ Experimental shear capacity, $\mathrm{kN}$

$\varepsilon_{c}^{0} \quad$ Initial concrete compressive strain

$\varepsilon_{c}^{i} \quad$ Concrete compressive strain

$\varepsilon_{c}^{u} \quad$ Maximum usable compressive strain in the concrete

$\varepsilon_{x}^{i} \quad$ Strain in the tension reinforcement associated to $\varepsilon_{c}^{i}$

$\rho \quad$ Longitudinal (flexure) reinforcement ratio, $A_{s} / b_{w} d$

$\psi^{i} \quad$ Curvature of the cross-section of the beam associated to $\varepsilon_{c}^{i}$

\section{Introduction}

The extensive research on the flexural behaviour of reinforced and prestressed concrete members has clarified mechanisms to such an extent that well-understood conclusions are now incorporated in most of the current design codes. However, the dilemma of the shear behaviour of reinforced and prestressed concrete members has not been settled in spite of the extensive research. Shear behaviour in reinforced and prestressed concrete members has been the subject of many controversies and debates since the turn of the last century. The shear mechanism is indeed a complex phenomenon involving many variables and cannot be rationalized into a simple model. Several models are introduced by different codes defining the design procedure and the applicability conditions (ACI 318 2014; Eurocode 2 2004; CSA Standard A23.3 2004). 
Shear failures in reinforced and prestressed concrete members are sudden and catastrophic in nature and should be avoided in the design process. That is why reinforced concrete members are first dimensioned in flexure and then verified for shear. The effect of shear is to induce tensile stresses which may result in diagonal cracks. Diagonal cracks occur when these stresses along with the longitudinal stresses due to bending exceed the tensile strength of concrete. Unless appropriate amounts of web reinforcement have been provided, these diagonal cracks can result in a premature shear failure. Most of the shear design provisions superimpose the shear strength of a flexural reinforced concrete member into two components. The two components comprise the concrete contribution to shear strength, $V_{c}$, and the shear reinforcement contribution, $V_{s}$. The provisions give separate design equations for evaluating $V_{c}$ and $V_{s}$. The design shear strength is therefore the summation of $V_{c}$ and $V_{s}$, multiplied by a suitable strength or material reduction factor.

Generally, the concrete contribution $V_{c}$ to shear strength of reinforced concrete beams is affected by five principal variables. These variables include the concrete tensile strength, $f_{t}$, usually expressed as a function of the compressive strength; the longitudinal reinforcement ratio, $\rho=A_{s} / b_{w} d$; the shear span to depth ratio, $a_{v} / d$ or $M / V d$; the axial force or amount of prestressing, if exists; and the depth of the member to account for size effect (ACI-ASCE 445 2009). Several multi-parameter empirical equations have been developed for evaluating $V_{c}$ shear component (Kim and Park 1996; Rebeiz 1999; Okamura and Higai 1980; and Zsutty 1968). However, shear empirical equations have been recognized to produce a large degree of scatter due to the scatter in test results and to the uncertainty in assessing the influence of complex parameters in a simple formula (ACIASCE-445 2009).

Previous studies have indicated that shear strength in concrete beams decreases with increase in strain in the longitudinal reinforcement through various hypotheses (Vecchio and Collins 1986; CSA Committee A23.3 2004; AASHTO 2008; Muttoni and Ruiz 2008). Another family of theoretical models relates concrete shear strength to the strain in the longitudinal reinforcement through various hypotheses regarding the crack location, orientation and the state of strain or stress (Zararis and Papadakis 2001; Tureyen and Frosch 2003; Park et al. 2006; Jeong and Kim 2014). Recently, Shuraim (2014) introduced an approach, which relates the shear strength capacity or shear resistance in a concrete beam with the internal shear resulting from applied load, thus termed as shear demand.

This investigation focuses on evaluating the shear strength of reinforced concrete beams without transverse reinforcement. This study is of a relevant importance to structural concrete members that are constructed without transverse reinforcement such as slabs, footings, joists, and lightly stressed members. The beams were cast using concrete strength of 55-60 MPa representing the low class of high strength concrete (HSC) that is commonly used in HSC applications in the local construction industry. One feature of HSC that affects the structural response is the tendency of cracks to pass through instead of around the aggregates due to the smaller difference between the strength of aggregate and concrete matrix. This creates smoother crack surfaces, reducing the contribution of aggregate interlock and hence, reducing the shear force carried by concrete $V_{c}$ (El-Sayed et al. 2006; Harkouss and Hamad 2015). As a result, higher dowel forces occur in the longitudinal reinforcing bars. These higher dowel forces together with the highly concentrated bond stresses in HSC beams, result in higher bond-splitting stresses where the shear cracks cross the longitudinal tension bars. These combined effects can lead finally to brittle shear failures. The applicability of the resistance-demand procedure is examined by comparing the predictions of the procedure with the experimental shear strength of the beams. The results of the comparison are presented and discussed.

\section{Resistance-Demand Procedure for Shear}

The design procedure developed earlier (Shuraim 2014) involves two elements. First, shear resistance relationship which expresses the shear degradation as a function of the longitudinal strain in the bottom reinforcement, among other variables. Second, shear demand relationship which represents the required shear as the applied load increases, and also can be expressed as a function of the longitudinal strain in the bottom reinforcement. Typical curves are shown in Fig. 1.

\subsection{Shear Versus Strain Relationship}

The shear resistance-longitudinal strain relationship is expressed as follows:

$$
V_{R}^{i}=\frac{0.63}{1+500 \varepsilon_{x}^{i}} f_{c}^{\prime 1 / 3} b_{w} d
$$

where $f_{c}^{\prime}$ is the concrete compressive strength, $b_{w}$ is the web width of the beam, and $d$ is the effective depth of the bottom reinforcement. Finally, the longitudinal strain is expressed as follows with reference to Fig. 2 .

$$
\varepsilon_{x}^{i}=\psi^{i} d-\varepsilon_{c}^{i}
$$




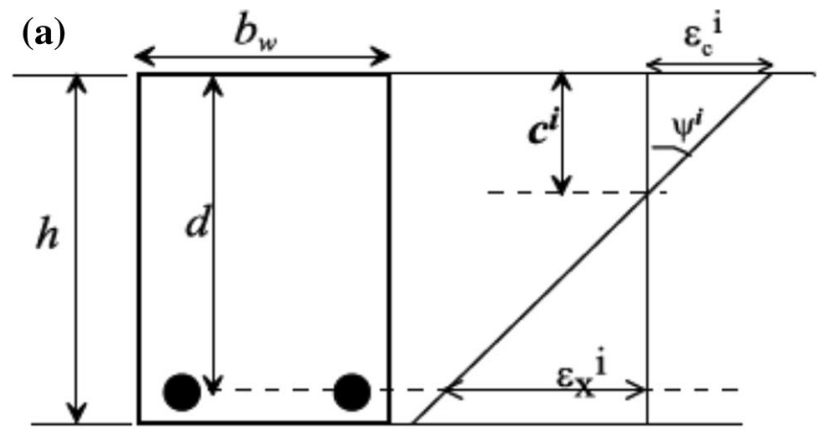

(b)

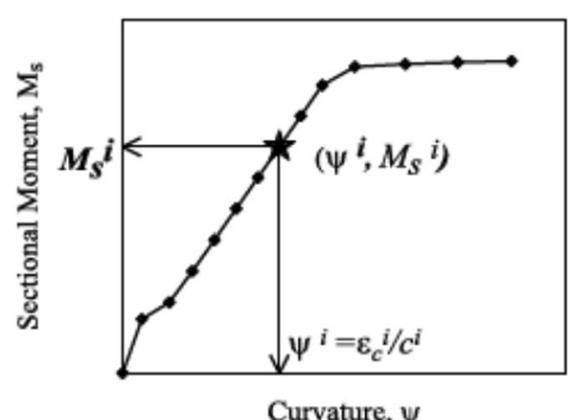

(c)

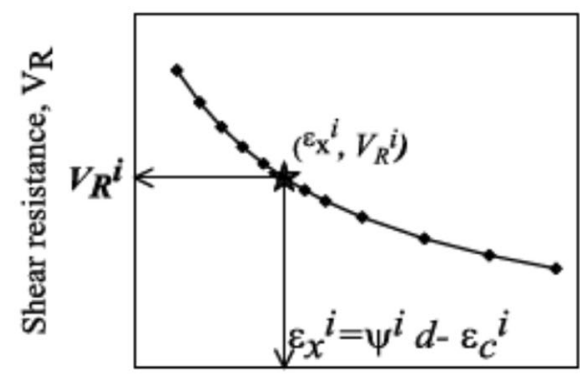

Rebar strain, $\varepsilon_{\mathbf{x}}$

Fig. 2 Schematic steps for developing shear resistance curve.

Figure 2a shows a linear strain distribution in a typical reinforced concrete cross section of a simple beam under arbitrary static loading. $\varepsilon_{c}^{i}$ is the compressive strain at the top layer while $c^{i}$ is the depth of the neutral axis measured from the compression face. Under such assumptions, the curvature will be $\psi^{i}=\varepsilon_{c}^{i} / c^{i}$. Figure $2 \mathrm{~b}$ shows typical moment-curvature relationship that can be developed in incremental form by increasing the top strain $\varepsilon_{c}^{i}$, and adjust the neutral axis depth in order to satisfy equilibrium, from which the associated sectional moment, $M_{s}^{i}$, is obtained. The results of $\varepsilon_{c}^{i}, \psi^{i}$, and $M_{s}^{i}$ are to be tabulated in order to compute $\varepsilon_{c}^{i}$ and $V_{R}^{i}$ as per Eqs. (1) and (2).

\subsection{Shear Demand Curve}

For a simply supported beam subjected to two concentrated loads, $V_{D}^{i}$, at a shear span, $a_{v}$, the internal shear force and moment diagrams are as shown in Fig. 3. The shear demand that is associated with a particular shear resistance and longitudinal strain, $\varepsilon_{x}^{i}$, is computed from $M_{s}^{i}$ and $a_{v}$, such that:

$$
V_{D}^{i}=M_{s}^{i} / a_{v}
$$
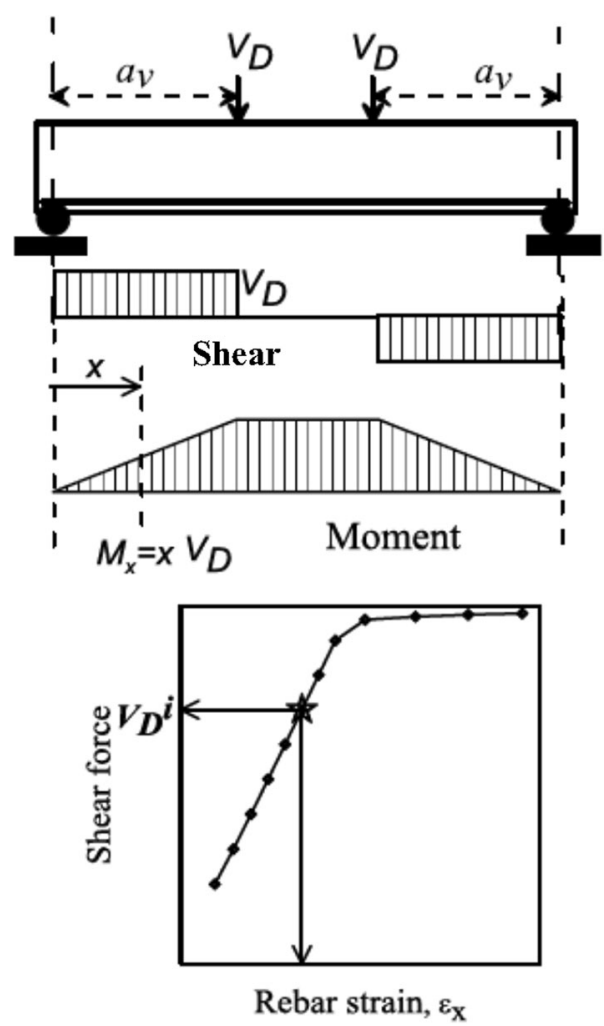

Fig. 3 Schematic steps for developing shear demand curve.

Repeating the process for a sufficient number of concrete top strains such that $\left(\varepsilon_{c}^{0} \leq \varepsilon_{c}^{i} \leq \varepsilon_{c}^{u}\right)$ is to be performed in order to generate the demand and resistance curves $\left(\varepsilon_{x}^{i}, V_{D}^{i}, V_{R}^{i}\right)$.

Therefore for any top strain value, $\varepsilon_{c}^{i}$, the associate values for $\psi^{i}, M_{s}^{i}, \varepsilon_{x}^{i}, V_{R}^{i}$ and $V_{D}^{i}$ become readily available. The next step is to graph $V_{R}^{i}$ and $V_{D}^{i}$ versus the strain as shown in Fig. 4, where the shear demand follows an ascending path while the shear resistance follows a descending path. Their intersection point defines the basic shear strength, $V_{R D}$, for a normal size beam without stirrups.

\subsection{Size Effect Factor}

Studies (ACI-ASCE Committee 445 2009) have shown that there is a significant size effect or depth of member effect on the shear strength of members without transverse

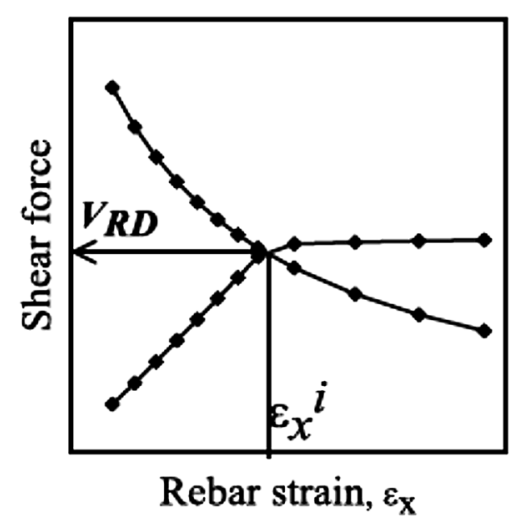

Fig. 4 Defining basic shear: the intersection of the resistance and demand curves. 
reinforcement where the average shear stress to cause failure decreases with the increase of the effective depth. Several models have been proposed in the literature to account for such an effect. This study adopts a size reduction factor following the Canadian Standard CSA S806 (2012). The size factor is to modify the basic shear strength, such that:

$$
V_{R D}^{*}= \begin{cases}V_{R D} & d \leq 300 \mathrm{~mm} \\ \frac{750}{450+d} V_{R D} & d>300 \mathrm{~mm}\end{cases}
$$

\section{Experimental Program}

The experimental program described in this paper consisted of shear tests on 18 full-scale reinforced concrete beams without stirrups. The test variables included the amount of longitudinal reinforcement, the shear span to depth ratio, and the beam depth.

\subsection{Material Characteristics}

The target compressive concrete strength of the concrete used in the beams was 55-60 MPa after 28 days which represents the lower category of HSC. The concrete was provided by a local ready-mix supplier. Table 1 gives the mix proportions of the concrete used in this study. Standard concrete cylinders $150 \times 300 \mathrm{~mm}$ were cast during casting the beams and cured under the same conditions as the test beams. The average compressive strength at the time of beam testing, based on standard tests on concrete cylinders, ranged between 59.6 and $64.3 \mathrm{MPa}$.

Deformed steel bars were used in reinforcing the test beams. Steel bars with diameters of 12, 14, 18, and $20 \mathrm{~mm}$ were used as main tensile reinforcement while steel bars with diameter of $10 \mathrm{~mm}$ were used as top reinforcement. The actual tensile properties of the reinforcing bars were determined using standard tensile tests performed on three samples of each bar size. The actual properties of the bars are given in Table 2.

\subsection{Test Specimens}

A total of 18 full-scale reinforced concrete beams were constructed and tested up to failure. The test beams were divided into two main groups according to the beam depth. Group I comprised 9 beams with a total depth of $700 \mathrm{~mm}$ and Group II comprised 9 beams with a total depth of $400 \mathrm{~mm}$. Three different reinforcement ratios, $\rho$, of 0.73 , 1.21 , and $1.83 \%$ were used along with three different $a_{v} / d$ ratios of 3,4 , and 5 . All beams had the same beam width of $250 \mathrm{~mm}$ and the beam length was $6.0-7.3$ and $4.5 \mathrm{~m}$ for beams of Group I and II, respectively.

All beams had overhang length of 252-345 $\mathrm{mm}$ beyond the supports on each side as anchorage length for the reinforcing steel to avoid premature bond failures prior to shear failures. In addition, both overhangs behind the supports were provided with $8 \mathrm{~mm}$-diameter steel stirrups (3 stirrups each) to enhance the bond behavior and to fix the longitudinal bars in their positions. No stirrups were included within the shear span of the beams between the point load and support. The details of the test specimens are given in Table 3 and shown in Figs. 5 and 6. The designation of the beams uses the character B standing for beam and the first number 700 or 400 refers to the beam depth. The second number (3 to 5) stands for $a_{v} / d$ ratio. The characters $\mathrm{r} 1, \mathrm{r} 2$, and $\mathrm{r} 3$ refer to the reinforcement ratio of $0.73,1.21$, and $1.83 \%$, respectively.

\subsection{Test Setup and Instrumentation}

The beams were simply-supported and tested in four-point bending. Each tested beam was loaded directly on the top compressive face with two equally concentrated loads according to the considered $a_{v} / d$ and supported at the bottom. The beams were tested using closed-loop Instron actuator with a capacity of $500 \mathrm{kN}$.

Electrical resistance strain gauges were attached to the reinforcement and concrete surface. In each beam, electrical resistance strain gauges were bonded to the reinforcing steel at various locations along the length of the beam and were bonded to the top concrete surface at midspan of the beams. The deflection at midspan was measured using two LVDTs at each side of the beam. During testing, load was monotonically applied at a stroke-controlled rate of $1.0 \mathrm{~mm} / \mathrm{min}$ and the formation of the cracks on the sides of the beams were also marked and

Table 1 Concrete mix proportions.

\begin{tabular}{c|c}
\hline Water-cement ratio & 0.37 \\
\hline Water $\left(\mathrm{kg} / \mathrm{m}^{3}\right)$ & 167 \\
\hline Cement content $\left(\mathrm{kg} / \mathrm{m}^{3}\right)$ & 450 \\
\hline Fine aggregate content $\left(\mathrm{kg} / \mathrm{m}^{3}\right)$ & 787 \\
\hline Coarse aggregate size $(\mathrm{mm})$ & $9.5-19$ \\
\hline Coarse aggregate content $\left(\mathrm{kg} / \mathrm{m}^{3}\right)$ & 971 \\
\hline High-range water-reducing admixture $\left(\mathrm{L} / \mathrm{m}^{3}\right)$ & 3 \\
\hline Air $(\%)$ & 2 \\
\hline Slump $(\mathrm{mm})$ & 140 \\
\hline
\end{tabular}


Table 2 Properties of reinforcing steel.

\begin{tabular}{c|c|c|c}
\hline Bar diameter $(\mathrm{mm})$ & Yield strength $(\mathrm{MPa})$ & Ultimate strength $(\mathrm{MPa})$ & Modulus of elasticity $(\mathrm{GPa})$ \\
\hline 10 & 533 & 765 & 195 \\
\hline 12 & 569 & 658 & 207 \\
\hline 14 & 565 & 671 & 183 \\
\hline 18 & 546 & 671 & 179 \\
\hline 20 & 542 & 666 & 179 \\
\hline
\end{tabular}

Table 3 Details of test beams.

\begin{tabular}{|c|c|c|c|c|c|c|c|c|c|c|c|}
\hline & $\mid \begin{array}{c}\text { Beam } \\
\text { designation } \\
\left(\mathrm{B}-\mathrm{h}-\mathrm{a}_{\mathrm{v}} /\right. \\
\mathrm{d}-\mathrm{r})\end{array}$ & $\begin{array}{c}\text { Target } \\
f_{c}^{\prime} \\
\mathrm{MPa}\end{array}$ & $h(\mathrm{~mm})$ & $d$ & $a_{v} / d$ & $a_{v}$ & $a_{f}$ & ex (mm) & $\begin{array}{c}\text { Length } \\
(\mathrm{mm})\end{array}$ & Sec. \# & $\rho$ \\
\hline \multicolumn{12}{|c|}{ Group I: $700 \mathrm{~mm}$-depth beams } \\
\hline 1 & B700-5-r1 & 60 & 700 & 612 & 5 & 3060 & 600 & 580 & 7300 & 1 & 0.73 \\
\hline 2 & B700-5-r2 & 60 & 700 & 612 & 5 & 3060 & 600 & 580 & 7300 & 2 & 1.21 \\
\hline 3 & B700-5-r3 & 60 & 700 & 612 & 5 & 3060 & 600 & 580 & 7300 & 3 & 1.83 \\
\hline 4 & B700-4-r1 & 60 & 700 & 612 & 4 & 2448 & 600 & 504 & 6000 & 1 & 0.73 \\
\hline 5 & B700-4-r2 & 60 & 700 & 612 & 4 & 2448 & 600 & 504 & 6000 & 2 & 1.21 \\
\hline 6 & B700-4-r3 & 60 & 700 & 612 & 4 & 2448 & 600 & 504 & 6000 & 3 & 1.83 \\
\hline 7 & B700-3-r1 & 60 & 700 & 612 & 3 & 1836 & 1800 & 528 & 6000 & 1 & 0.73 \\
\hline 8 & B700-3-r2 & 60 & 700 & 612 & 3 & 1836 & 1800 & 528 & 6000 & 2 & 1.21 \\
\hline 9 & B700-3-r3 & 60 & 700 & 612 & 3 & 1836 & 1800 & 528 & 6000 & 3 & 1.83 \\
\hline \multicolumn{12}{|c|}{ Group II: 400 mm-depth beams } \\
\hline 10 & B400-5-r1 & 60 & 400 & 335 & 5 & 1675 & 600 & 550 & 4500 & 4 & 0.74 \\
\hline 11 & B400-5-r2 & 60 & 400 & 335 & 5 & 1675 & 600 & 550 & 4500 & 5 & 1.22 \\
\hline 12 & B400-5-r3 & 60 & 400 & 335 & 5 & 1675 & 600 & 550 & 4500 & 6 & 1.82 \\
\hline 13 & B400-4-r1 & 60 & 400 & 335 & 4 & 1340 & 1300 & 520 & 4500 & 4 & 0.74 \\
\hline 14 & B400-4-r2 & 60 & 400 & 335 & 4 & 1340 & 1300 & 520 & 4500 & 5 & 1.22 \\
\hline 15 & B400-4-r3 & 60 & 400 & 335 & 4 & 1340 & 1300 & 520 & 4500 & 6 & 1.82 \\
\hline 16 & B400-3-r1 & 60 & 400 & 335 & 3 & 1005 & 1800 & 690 & 4500 & 4 & 0.74 \\
\hline 17 & B400-3-r2 & 60 & 400 & 335 & 3 & 1005 & 1800 & 690 & 4500 & 5 & 1.22 \\
\hline 18 & B400-3-r3 & 60 & 400 & 335 & 3 & 1005 & 1800 & 690 & 4500 & 6 & 1.82 \\
\hline
\end{tabular}

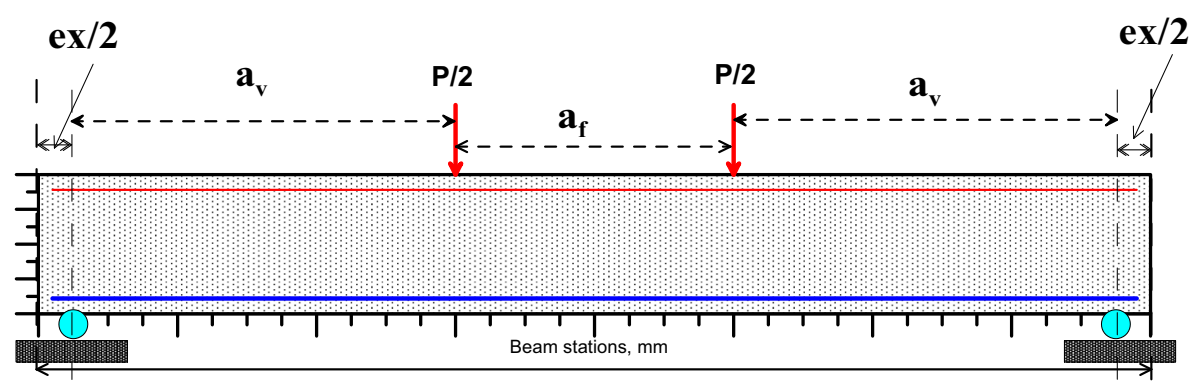

Fig. 5 Typical beam setup. 


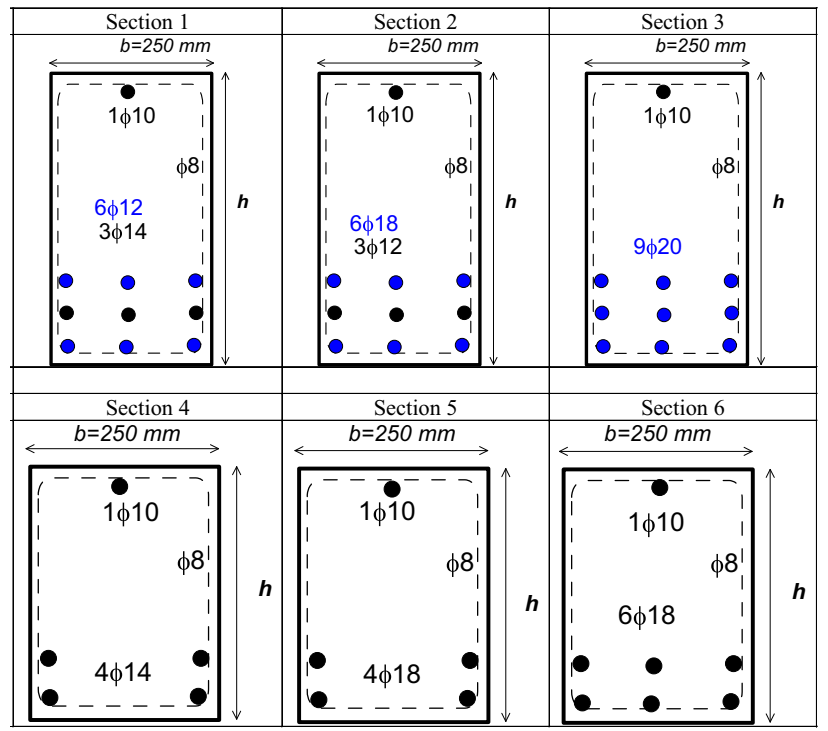

Fig. 6 Typical cross-sections of beams.

recorded. The applied load, displacements, and strain readings were electronically recorded during the test using a data acquisition system.

\section{Test Results and Discussion}

A summary of the beam test results is presented in Table 4. It should be noted that each beam was symmetrically loaded with two concentrated loads and consequently, the shear force equals half the total applied load.

\subsection{Load Deflection Response}

The applied load versus midspan deflection plots for the tested beams are shown in Fig. 7. Each plot presents the deflection response of beams with different $\rho$ but having the same $a_{v} / d$. Table 4 gives also the midspan deflection at failure for each beam. The load-deflection relationship was approximately bilinear for all beams except beam B400-5-r1 with lower $\rho$ which showed trilinear behavior. For each figure and for the bilinear behavior, the first part of the loaddeflection plot up to flexural cracking was similar representing the behavior of the uncracked beam utilizing the gross moment of inertia of the concrete cross-section. The second part, post- cracking up to failure, represents the cracked beam with reduced moment of inertia. In this part, the flexural stiffness of the tested beams was affected by the amount of reinforcement showing increased stiffness with

Table 4 Summary of test results.

\begin{tabular}{|c|c|c|c|c|c|c|c|}
\hline \multirow[t]{2}{*}{ Beam } & \multirow[t]{2}{*}{$f_{c}^{\prime}(\mathrm{MPa})$} & \multirow{2}{*}{$\begin{array}{l}\text { Load at failure } \\
\qquad(\mathrm{kN})\end{array}$} & \multirow{2}{*}{$\begin{array}{c}\text { Ultimate shear } \\
V_{u \exp }(\mathrm{kN})\end{array}$} & \multirow{2}{*}{$\begin{array}{c}\text { Midspan } \\
\text { deflection at } \\
\text { failure }(\mathrm{mm})\end{array}$} & \multicolumn{2}{|c|}{ Midspan strain $(\mu \varepsilon)$} & \multirow[t]{2}{*}{ Failure mode* } \\
\hline & & & & & Bars & Concrete & \\
\hline \multicolumn{8}{|c|}{ Group I: 700 mm-depth beams } \\
\hline B700-5-r1 & \multirow[t]{9}{*}{64.3} & 209 & 104.5 & 28.3 & 3191 & -975 & DT \\
\hline B700-5-r2 & & 260 & 130 & 23.8 & 2754 & -1150 & DT \\
\hline B700-5-r3 & & 286 & 143 & 19.1 & 1533 & -1032 & DT \\
\hline B700-4-r1 & & 211 & 105.5 & 14.1 & 2213 & -1283 & DT \\
\hline B700-4-r2 & & 280 & 140 & 13.3 & 1938 & -690 & DT \\
\hline B700-4-r3 & & 324 & 162 & 11.7 & 1620 & -843 & DT \\
\hline B700-3-r1 & & 232 & 116 & 12.8 & 2264 & -764 & DT \\
\hline B700-3-r2 & & 312 & 156 & 13.0 & 1568 & -709 & DT \\
\hline B700-3-r3 & & 408 & 204 & 15.3 & 1502 & -535 & DT \\
\hline \multicolumn{8}{|c|}{ Group II: 400 mm-depth beams } \\
\hline B400-5-r1 & \multirow[t]{9}{*}{59.6} & 135 & 67.5 & 59.8 & 9013 & $* *$ & FL \\
\hline B400-5-r2 & & 154 & 77 & 16.3 & 2578 & -960 & DT \\
\hline B400-5-r3 & & 215 & 107.5 & 15.6 & 2359 & -1128 & DT \\
\hline B400-4-r1 & & 155 & 77.5 & 20.3 & 4198 & $* *$ & DT \\
\hline B400-4-r2 & & 215 & 107.5 & 19.6 & 2798 & -1025 & DT \\
\hline B400-4-r3 & & 243 & 121.5 & 15.7 & 2014 & -975 & DT \\
\hline B400-3-r1 & & 207 & 103.5 & 19.2 & 2840 & -955 & DT \\
\hline B400-3-r2 & & 260 & 130 & 20.2 & 2472 & -902 & DT \\
\hline B400-3-r3 & & 275 & 137.5 & 12.6 & 1638 & -868 & DT \\
\hline
\end{tabular}

* DT diagonal tension, $F L$ flexural failure.

** Strain gauge malfunctioned. 

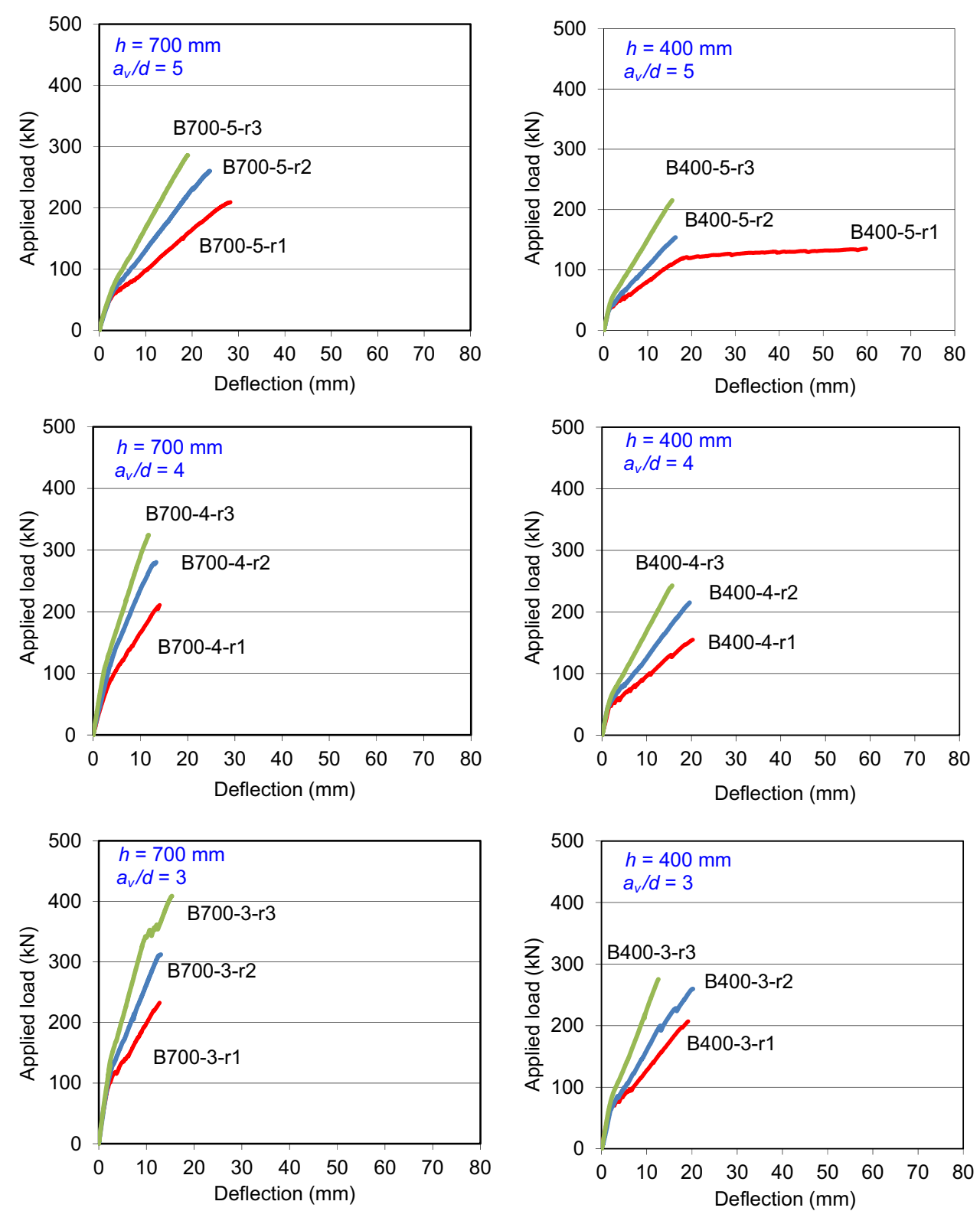

Fig. 7 Load-deflection relationship.

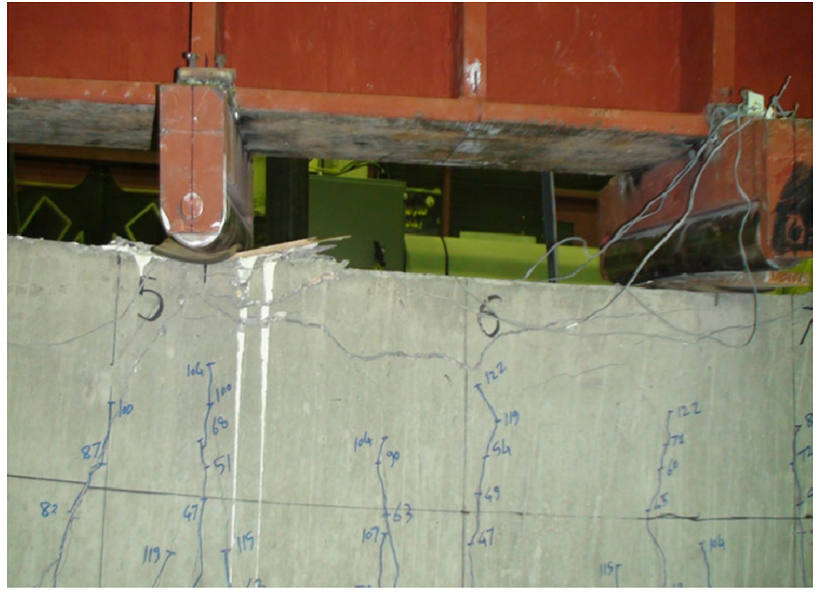

Fig. 8 Flexural crushing of beam B400-5-r1.

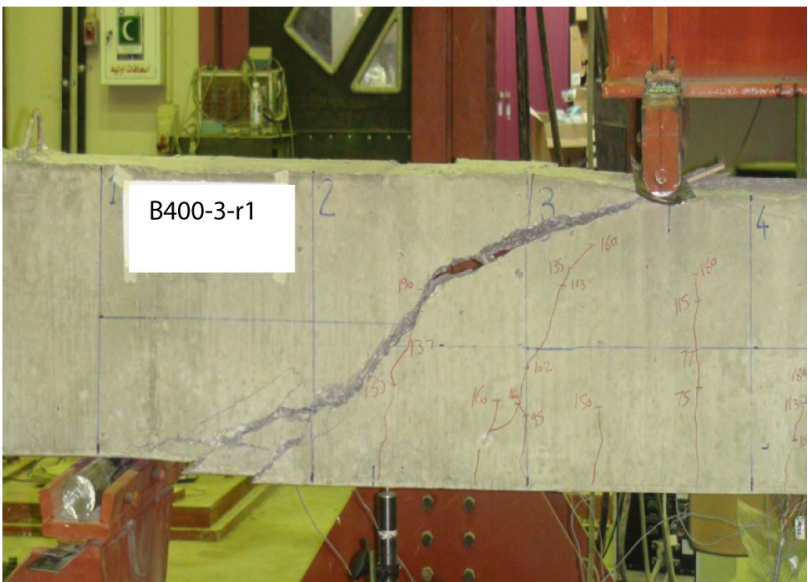

Fig. 9 Typical diagonal tension failure (B400-3-r1). 


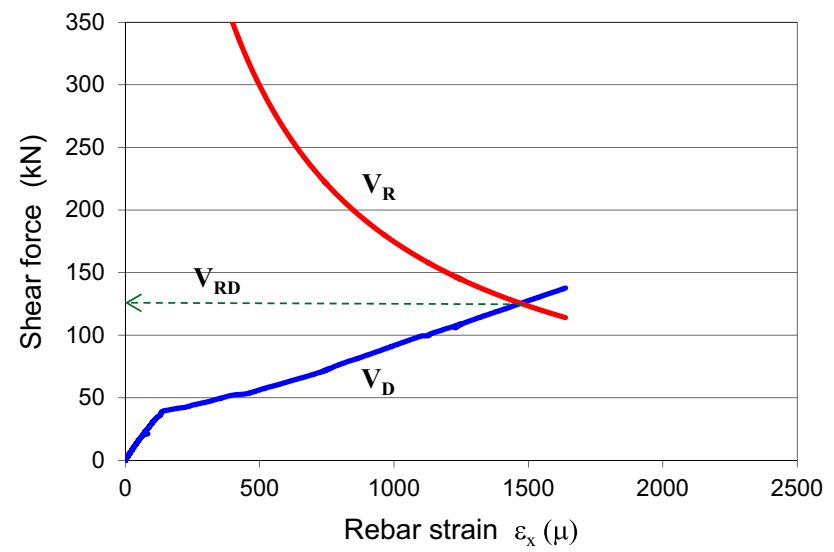

Fig. 10 Typical shear resistance and demand curves against rebar strain (B400-3-r3).
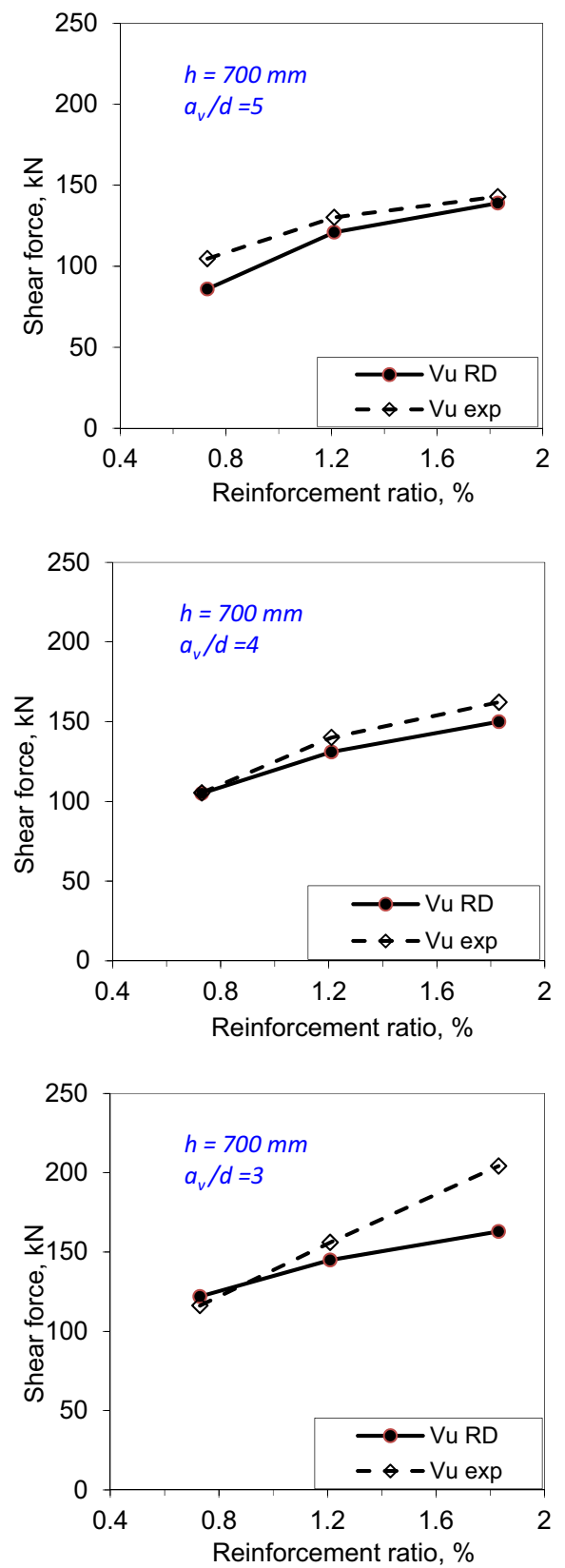

the increase of $\rho$. Beam B400-5-r1 of trilinear behavior showed yielding plateau in the third part of the curve indicating that the reinforcing steel yielded before shear failure.

\subsection{Crack Patterns and Modes of Failure}

Similar characteristics of crack patterns were observed for all eighteen beams. Crack formation was initiated in the flexural span between the two concentrated loads where the flexural stress is highest and shear stress is zero. The cracks were vertical perpendicular to the direction of the maximum principal tensile stress induced by pure bending. As load increased, additional flexural cracks opened within the shear span. However, because of the dominance of the shear stresses, the cracks became progressively more inclined and propagated towards the load points leading finally to diagonal tension failure. The failure
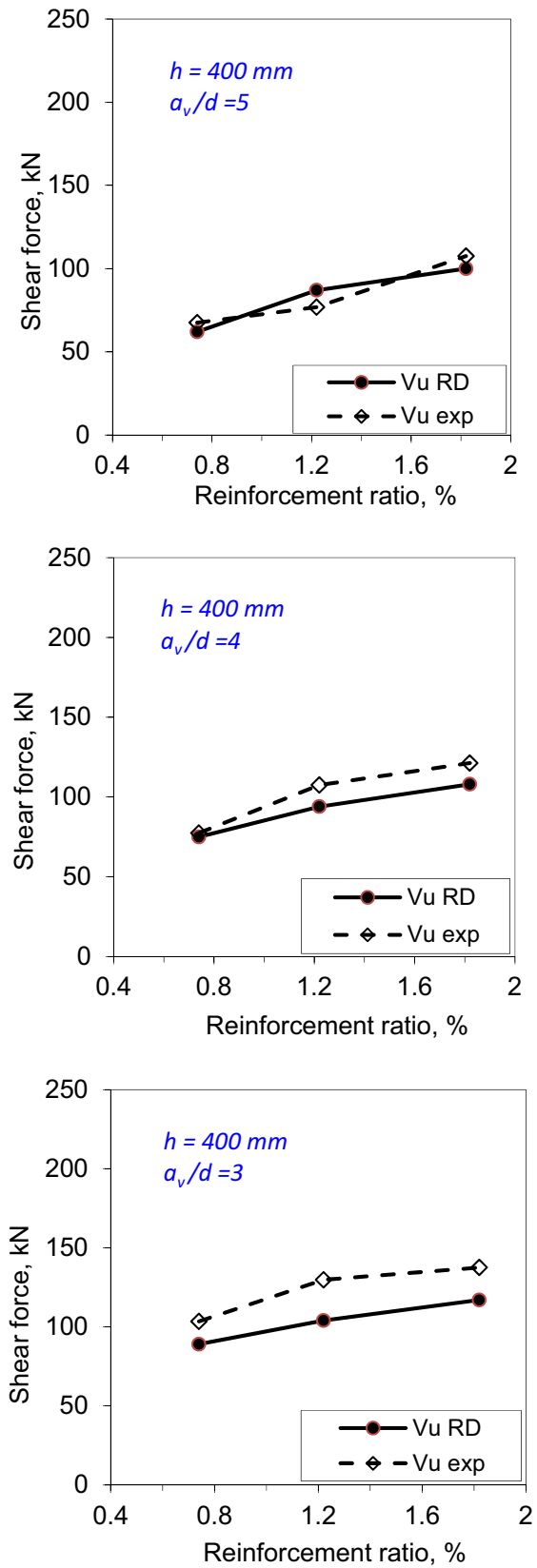

Fig. 11 Ultimate shear strength versus reinforcement ratio. 

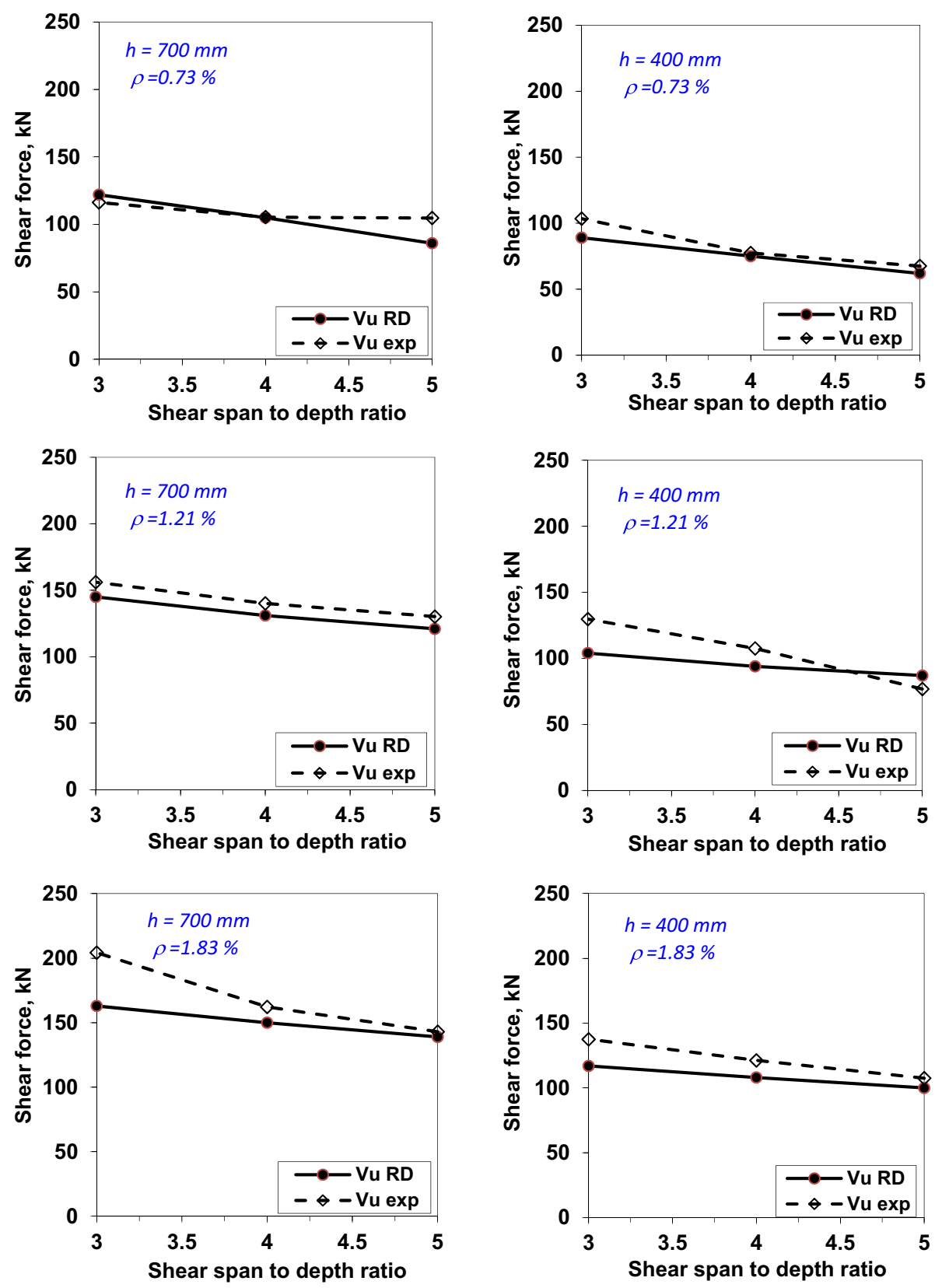

Fig. 12 Ultimate shear strength versus shear span to depth ratio.

modes of the eighteen beams are given in the last column of Table 4. All beams failed in diagonal tension except beam B400-5-r1 which failed in flexure by yielding of the reinforcing steel followed by concrete crushing. Figures 8 and 9 illustrate by photographs the flexural failure mode of beam B400-5-r1 and the typical diagonal tension failure mode of the beams of this investigation.

\subsection{Strain in Reinforcement and Concrete}

Table 4 gives the measured midspan strains in the reinforcement and concrete at failure for each beam. The concrete compressive strains at failure ranged from 535 to 1283 micro-strain. The tensile steel strains were lower than the average yield strain of 2900 micro-strain for the majority of the beams, as given in Table 4. For beam B400-5-r1 that showed yielding plateau (Fig. 7), the maximum steel strains measured was 9013 micro-strain. Beams B700-5-rland
B400-4-r1showed slightly higher steel strain than the average yield strain; indicating that the two beams started steel yielding prior to the onset of shear failure.

\subsection{Ultimate Shear Strength}

All beams failed in diagonal tension shortly after the formation of the critical diagonal crack except beam B400-5rlwhich failed in flexure. The shear strength of flexural members without web reinforcement is identified by the formation of the critical inclined crack and the subsequent sudden drop in load carrying capacity. In general, for members with a shear span to depth ratio, $a_{v} / d$, greater than 2.5, the difference between the critical inclined cracking shear capacity $V_{c r}$ and the ultimate shear capacity $V_{u}$ is small. Therefore, for such members, the inclined cracking shear capacity can be assumed to be the same as the ultimate shear capacity for all practical purposes (Tureyen and Frosch 
2003). In addition, shear strength at ultimate failure is a more defined and reliable measure than cracking shear strength (Rebeiz 1999). This investigation adopts the ultimate shear capacity $V_{u}$ as the concrete shear capacity $V_{c}$. The experimental ultimate shear strengths, $V_{u}$ exp, of the tested beams are given in Table 4.

The effect of the amount of the steel reinforcement on the ultimate shear strength of the tested beams is shown in Fig. 10 for the two groups of beams. The vertical axis in the figure represents the experimental ultimate shear strength while the horizontal axis represents the reinforcement ratio, $\rho$. It can be noted that increasing $\rho$ from 0.73 to $1.21 \%$ increased the shear strength by 24 to $34 \%$ for beams of Group I and by 14 to $39 \%$ for the beams of Group II. Also, increasing $\rho$ from 1.21 to $1.83 \%$ increased the shear strength of Group I-beams by 10 to $31 \%$ and increased the shear strength of Group II-beams by 6 to $40 \%$.
The variations in ultimate shear strength with the shear span-to-depth ratio, $a_{v} / d$, are shown in Fig. 11 for the two groups of beams. The figure shows that the ultimate shear strength increased with decreasing $a_{v} / d$. Decreasing $a_{v} / d$ from 5 to 4 , increased the shear strength by 1 to $13 \%$ for Group I-beams and by 13 to $40 \%$ for Group II-beams. In addition, decreasing $a_{v} / d$ from 4 to 3 increased the shear strength by 10 to $26 \%$ for Group I-beams and by 13 to $24 \%$ for Group II-beams.

To show the effect of the beam depth on the shear strength of the test beams, the test results of beams of Group I were compared with their counterparts of Group II which had the same $\rho$ and $a_{v} / d$, as presented in Fig. 12. In this figure, the shear stresses at failure were plotted against the beam effective depth. The shear stresses were normalized with respect to the cube root of concrete compressive strength to account for the difference in concrete strength

Table 5 Comparison of RD predictions and experimental results.

\begin{tabular}{|c|c|c|c|c|}
\hline \multicolumn{2}{|c|}{ Beam } & \multirow{2}{*}{$\begin{array}{l}\text { Ultimate shear } \\
V_{u \exp }(\mathrm{kN}) \\
104.5\end{array}$} & \multirow{2}{*}{$\begin{array}{c}V_{R D}^{*} \\
(\mathrm{kN})\end{array}$} & \multirow{2}{*}{$\begin{array}{c}V_{u \exp } / V_{R D}^{*} \\
1.22\end{array}$} \\
\hline Group I & B700-5-r1 & & & \\
\hline & B700-5-r2 & 130 & 121 & 1.07 \\
\hline & B700-5-r3 & 143 & 139 & 1.03 \\
\hline & B700-4-r1 & 105.5 & 105 & 1.0 \\
\hline & B700-4-r2 & 140 & 131 & 1.07 \\
\hline & B700-4-r3 & 162 & 150 & 1.08 \\
\hline & B700-3-r1 & 116 & 122 & 0.95 \\
\hline & B700-3-r2 & 156 & 145 & 1.08 \\
\hline & B700-3-r3 & 204 & 163 & 1.25 \\
\hline & & Mean & & 1.08 \\
\hline & & SD & & 0.1 \\
\hline & & $\operatorname{COV}(\%)$ & & 9 \\
\hline \multirow[t]{12}{*}{ Group II } & B400-5-r1 & 67.5 & 62 & 1.09 \\
\hline & B400-5-r2 & 77 & 87 & 0.89 \\
\hline & B400-5-r3 & 107.5 & 100 & 1.08 \\
\hline & B400-4-r1 & 77.5 & 75 & 1.03 \\
\hline & B400-4-r2 & 107.5 & 94 & 1.14 \\
\hline & B400-4-r3 & 121.5 & 108 & 1.13 \\
\hline & B400-3-r1 & 103.5 & 89 & 1.16 \\
\hline & B400-3-r2 & 130 & 104 & 1.25 \\
\hline & B400-3-r3 & 137.5 & 117 & 1.18 \\
\hline & & Mean & & 1.1 \\
\hline & & SD & & 0.1 \\
\hline & & $\operatorname{COV}(\%)$ & & 9 \\
\hline
\end{tabular}



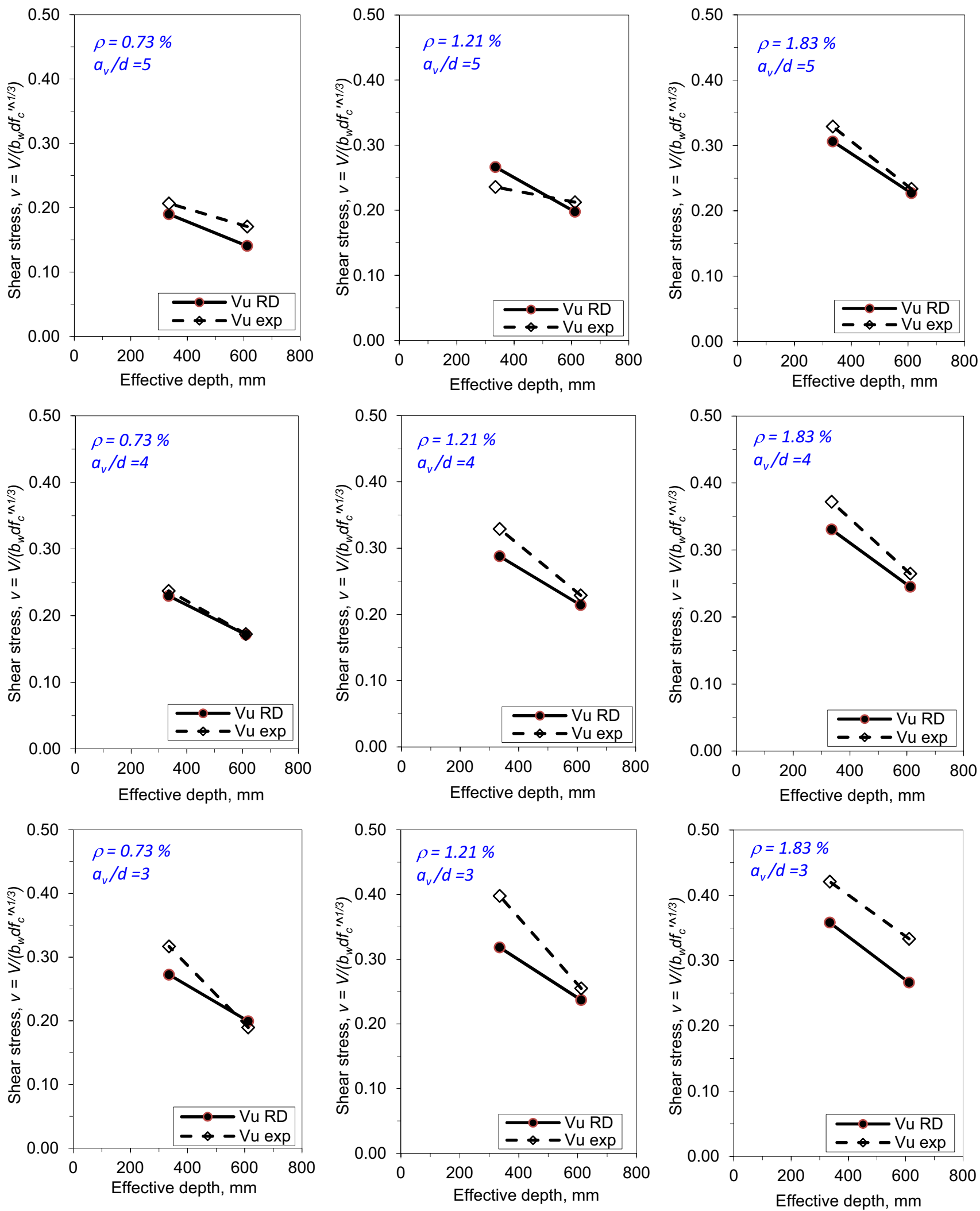

Fig. 13 Ultimate normalized shear stress versus beam depth.

between the two groups of beams. The figure indicates that all beams showed reduction in failure shear stresses with the increase in beam depth. Beams of $a_{v} / d=5$ showed reductions ranging between 10 and $29 \%$; beams of $a_{v}$ f $d=4$ showed reductions of 27 to $30 \%$, and beams of $a_{v}$ d $d=3$ showed reductions of 21 to $40 \%$. This result indicates that the extent of reduction in shear stresses appears to be affected by $a_{v} / d$ ratio as the reduction in shear stresses appears to increase with the decrease in $a_{v} / d$ ratio. On the other hand, it is not clear that the reduction in shear stresses due to the increase in beam depth is influenced by the reinforcement ratio. 


\section{Comparison of Resistance-Demand Predictions and Experimental Results}

The ultimate capacity of the test beams was predicted using the proposed resistance-demand procedure. The predicted shear strength $V_{R D}^{*}$ of the tested beams is given in Table 5. It should be pointed out that the shear strength of the beams was calculated at the critical section which is located at a distance $d$ from the point load. Figure 10 plots the shear resistance and shear demand curves against the rebar strain for beam B400-3-r3 as a typical. The figure indicates that both shear resistance and shear demand of the beam are strongly affected by the strain in the reinforcement. The intersection of the two curves gives the shear strength $V_{R D}$ of the beam. Then, $V_{R D}$ is multiplied by the size effect factor according to Eq. (4) to obtain the shear strength $V_{R D}^{*}$ of the beam.

A comparison of the predicted shear strength with the experimental ones is also provided in Table 5. The results of the comparison indicate accurate and consistent predictions for the ultimate shear strength of the tested beams. The average ratio of $V_{u \exp } / V_{R D}^{*}$ was 1.08 with a coefficient of variation of $9 \%$ for the beams of Group I while the corresponding values for beams of Group II were 1.1 and $9 \%$.

To further examine the proposed procedure for capturing the effect of the test parameters on the shear capacity of the tested beams, the predictions were compared with the experimental ones with the variation of $\rho, a_{v} / d$, and $d$ in Figs. 11, 12, and 13, respectively. The presentation of the prediction results versus the reinforcement ratio shows a proportional increase of shear strength with the increase of flexural reinforcement for all beams, as shown in Fig. 11.

Figure 12 presents the resistance-demand calculations versus the shear span to depth ratio. The figure shows that the proposed procedure captures the trend of the increase of shear capacity with the decrease of shear span to depth ratio.

The resistance-demand predictions represented in terms of normalized shear stresses are plotted against the beam depth in Fig. 13. The figure indicates that the size effect on shear strength is reflected by the proposed procedure as the predicted normalized shear stresses of the beams decreased with the increase of beam depth. It is interesting to notice that the level of accuracy for the predictions is approximately comparable for the two groups of the tested beams as the average ratio of $V_{u \text { exp }} / V_{R D}^{*}$ is almost the same for the two groups as given in Table 5. This indicates that the size effect factor considered in the proposed procedure is capable of capturing such an effect in a consistent way.

\section{Conclusions}

The shear strength and behavior of reinforced concrete beams with low class of HSC $\left(f_{c}^{\prime}=55-60 \mathrm{MPa}\right)$ were investigated and presented. A total of eighteen full-scale beams without web reinforcement were constructed and tested up to failure. The test variables included the reinforcement ratio, the shear span to depth ratio and the beam size. The shear strengths of the tested beams were analyzed using a rational procedure proposed based on resistance-demand approach. The main findings of the study can be summarized as follows:

1. In general, the shear strengths of the beams were increased with the increase of the longitudinal reinforcement ratio and with the decrease of the shear span to depth ratio. In addition, the shear stresses at failure decreased with the increase of beam depth indicating size effect.

2. One important feature of the proposed resistancedemand procedure is that both shear resistance and shear demand of the beams are dependent on the strain in the reinforcement. While the shear resistance of the beams decreases with the increase of the reinforcement strain, the shear demand increases.

3. The proposed procedure showed good and reliable predictions of the shear strength of the tested beams. The procedure was capable of capturing the effect of the design variables on the shear strength of the beams in terms of accuracy and consistency.

\section{Acknowledgments}

This Project was funded by the National Plan for Science, Technology and Innovation (MAARIFAH), King Abdulaziz City for Science and Technology, Kingdom of Saudi Arabia, Award Number (10-ADV1023-02). The help of the engineers and technicians in the Center of Excellence for Concrete Research \& Testing (CoE-CRT) and in the structural laboratory of Civil Engineering Department at King Saud University is highly appreciated.

\section{Open Access}

This article is distributed under the terms of the Creative Commons Attribution 4.0 International License (http://creativecommons.org/licenses/by/4.0/), which permits unrestricted use, distribution, and reproduction in any medium, provided you give appropriate credit to the original author(s) and the source, provide a link to the Creative Commons license, and indicate if changes were made.

\section{References}

AASHTO. (2008). AASHTO LRFD Bridge design specifications, American Association of State Highway and Transportation Officials.

ACI Committee 318. (2014). Building code requirements for structural concrete and commentary. ACI 318-14/ACI 318R-14, American Concrete Institute, Farmington Hills, MI, 519 pp. 
CAN/CSA S806-12. (2012). Design and construction of building components with fibre reinforced polymers. Canadian Standards Association, Rexdale, Canada, 187 pp.

CAN/CSA-A23.3-04. (2004). Design of concrete structures. Canadian Standards Association, Rexdale, Canada, 240 pp.

El-Sayed, A. K., El-Salakawy, E., \& Benmokrane, B. (2006). Shear capacity of high-strength concrete beams reinforced with FRP bars. ACI Structural Journal, 103(3), 383-389.

Eurocode 2. (2004). Design of concrete structures, Part 1-1: General rules and rules for buildings. European Committee for Standardization, Brussels, Belgium, $230 \mathrm{pp}$.

Harkouss, R. H., \& Hamad, B. S. (2015). Performance of high strength self-compacting concrete beams under different modes of failure. International Journal of Concrete Structures and Materials, 9(1), 69-88.

Jeong, J. P., \& Kim, W. (2014). Shear resistant mechanism into base components: Beam action and arch action in shearcritical RC members. International Journal of Concrete Structures and Materials, 8(1), 1-14.

Joint ACI-ASCE Committee 445 (Reapproved 2009). Recent approaches to shear design of structural concrete, ACI Manual of Concrete Practice, American Concrete Institute, Farmington Hills, MI, 56 pp.

Kim, J. K., \& Park, Y. D. (1996). Prediction of shear strength of reinforced concrete beams without web reinforcement. $A C I$ Materials Journal, 93(3), 213-222.
Muttoni, A., \& Ruiz, M. F. (2008). Shear strength of members without transverse reinforcement as function of critical shear crack width. ACI Structural Journal, 105(2), 163-172.

Okamura, H., \& Higai, T. (1980). Proposed design equation for shear strength of RC Beams without web reinforcement. Proceedings, Japan Society of Civil Engineering, 300, 131-141.

Park, H. G., Choi, K. K., \& Wight, J. K. (2006). Strain-based shear strength model for slender beams without web reinforcement. ACI Structural Journal, 103(6), 783-793.

Rebeiz, K. S. (1999). Shear strength prediction for concrete members. Journal of Structural Engineering, ASCE, 125(3), 301-308.

Shuraim, A. B. (2014). A novel approach for evaluating the concrete shear strength in reinforced concrete beams. Latin American Journal of Solids and Structures, 11(1), 93-112.

Tureyen, A. K., \& Frosch, R. J. (2003). Concrete shear strength: Another perspective. ACI Structural Journal, 100(5), 609-615.

Vecchio, F. J., \& Collins, M. P. (1986). The modified compression field theory for reinforced concrete elements subjected to shear. ACI Journal, 83(2), 219-231.

Zararis, P. D., \& Papadakis, G. (2001). Diagonal shear failure and size effect in RC beams without web reinforcement. Journal of Structural Engineering, ASCE, 127(7), 733-742.

Zsutty, T. C. (1968). Beam shear strength prediction by analysis of existing data. ACI Journal, 65(11), 943-951. 